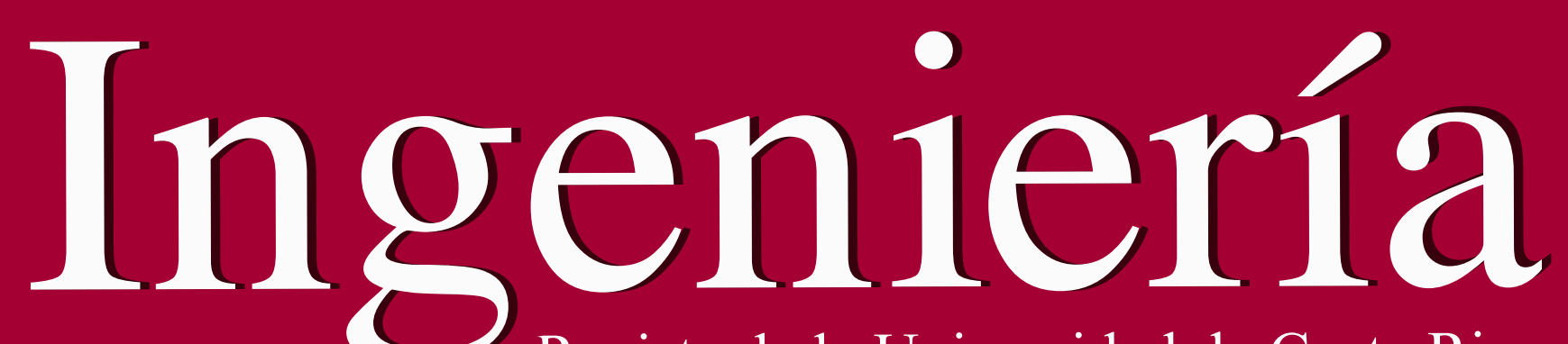

Revista de la Universidad de Costa Rica JULIO / DICIEMBRE 2020 - VOLUMEN 30 (2)

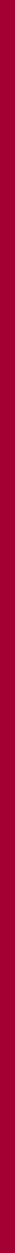




\title{
Heterogeneous Catalytic Ozonation of Phenol over Iron-based Catalysts in a Trickle Bed Reactor
}

\section{Ozonación catalítica heterogénea de fenol utilizando catalizadores de hierro en un reactor de lecho percolador}

\author{
Luis Briceño Mena, \\ School of Chemical Engineering, \\ University of Costa Rica, San José, Costa Rica \\ luis.bricenomena@ucr.ac.cr \\ ORCID: https://orcid.org/0000-0003-3684-4232 \\ J. Esteban Durán Herrera, \\ School of Chemical Engineering, \\ University of Costa Rica, San José, Costa Rica \\ esteban.duranherrera@ucr.ac.cr \\ ORCID: https://orcid.org/0000-0001-7382-0454
}

Recibido: 7 de octubre 2019

Aceptado: 14 de febrero 2020

\begin{abstract}
The use of continuous reactors for heterogeneous catalytic ozonation is yet to be investigated in order to develop a viable technology for industrial applications. This paper presents hydrodynamic and degradation studies on the use of a co-current down flow trickle bed reactor for heterogeneous catalytic ozonation of phenol (as model pollutant) over Fe-Diatomite pellets and Fe-coated glass beads. It was found that the reactor can operate under trickle or pulsing flow regimes, promoting mass transfer augmentation. Residence time distribution data, fitted with n-CSTR and axial dispersion (ADM) models, showed low axial dispersion and high flow distribution. Just the Fe-diatomite pellets showed important phenol adsorption (16\%). Degradation experiments demonstrated that phenol conversion was substantial when using both catalysts, up to $19,7 \%$ pollutant conversion with liquid-phase space times of just $6 \mathrm{~s}$. Compared to direct ozonation, the use of the Fe-diatomite pellets and Fe-coated glass beads enhanced the reactor performance by $48 \%$ and $23 \%$ respectively. It was confirmed that mass transfer is an important factor that restricts this reaction system performance; consequently, further improvement in mass transport rate is necessary for system optimization.
\end{abstract}

Keywords:

Heterogeneous catalytic ozonation; trickle bed reactor; emerging contaminants; advanced oxidation processes

\section{Resumen}

El uso de reactores continuos para la ozonización catalítica heterogénea es un tema que debe aún ser investigado con el objetivo de desarrollar una tecnología viable para aplicaciones industriales. Este artículo presenta estudios hidrodinámicos y de degradación utilizando un reactor de lecho percolador de flujos descendentes en co-corriente para la ozonización catalítica heterogénea de fenol (como contaminante modelo) 
sobre gránulos de Fe-diatomita y perlas de vidrio recubiertas con Fe. Se determinó que el reactor puede operar bajo regímenes de flujo percolador o pulsante, promoviendo el aumento de transferencia de masa. Los datos de distribución de tiempo de residencia, ajustados a los modelos de n-CSTR y de dispersión axial (ADM), mostraron baja dispersión axial y alta distribución de flujo. Solamente los gránulos de Fe-diatomita mostraron una adsorción de fenol (16\%) importante. Los experimentos de degradación demostraron que la conversión de fenol fue sustancial cuando se usaron ambos catalizadores, hasta un 19,7 \% de conversión del contaminante con espacio-tiempos de la fase líquida de solo $6 \mathrm{~s}$. En comparación con la ozonización directa, el uso de los gránulos de Fe-diatomita y las perlas de vidrio recubiertas con Fe mejoraron el rendimiento del reactor en un $48 \%$ y un $23 \%$ respectivamente. Se confirmó que la transferencia de masa es un factor importante que restringe el rendimiento de este sistema de reacción; en consecuencia, se necesita una mejora adicional en la velocidad de transporte másico para la optimización del sistema.

\section{Palabras clave:}

Ozonización catalítica heterogénea; reactor de lecho percolador; contaminantes emergentes; procesos de oxidación avanzada. 


\section{INTRODUCTION}

The presence of persistent organic pollutants (POPs) in water is a key environmental issue and one of the biggest challenges in wastewater and drinking water treatment (Peña-Guzmán et al. 2019), mainly because POPs are toxic and unresponsive to traditional treatment techniques. Occurrence of such pollutants can be related, for example, to petroleum, chemical products, pesticides, paints, and pharmaceuticals industries. One example of POPs is phenol, which can be found in many industrial wastewaters. Phenol is a highly soluble, stable, and toxic molecule that even at low concentrations can cause health problems. Also, at concentrations above $400 \mathrm{mg} / \mathrm{L}$, biological oxidation in conventional water treatment plants is not efficient due to phenol bactericide properties (Zeng et al., 2012). Because of all these issues, phenol is regulated in the USEPA Priority Pollutant List and its removal from industrial wastewater is important.

Among the different strategies for the abatement of POPs from wastewaters, those that involve the use of highly oxidative chemical species (particularly the hydroxyl radical) are of special interest. These technologies, known as advanced oxidation processes (AOPs), have proven to be effective for the degradation of phenolic compounds and other recalcitrant pollutants (Babu, Srivastava, Nidheesh \& Kumar, 2019). Specifically, ozone-based processes, in which ozone is used as the source of hydroxyl radicals, are an attractive alternative mainly due to the high degradation rates achievable at temperatures and pressures near to ambient conditions (Maugans \& Akgerman, 2003). Furthermore, by the use of proper catalysts, heterogeneous catalytic ozonation (HCO) has been considered as a way to improve ozonation processes, increasing pollutant and total organic carbon (TOC) removal rates and lowering ozone and energy consumption (Zhao, Ma, Zhizhong \& Zhai, 2008).

Most of the HCO research reported in the literature has been carried out using batch or semibatch reactors, utilizing high liquid/gas ratios and small catalyst particle size, mainly to promote favorable mass transfer conditions ( $\mathrm{Li}, \mathrm{Xu}$, Zhu, Ding \& Mahmood, 2010); however, those operation configurations are not suitable for industrial applications. In order to develop a continuous HCO-based technology for water treatment, three-phase phenomena and catalyst effects (such as diffusion, adsorption, $\mathrm{pH}$ changes, and surface reaction) must be addressed. Thus, mass transfer and fluid dynamics characterization of the solid-gas-liquid contact system is relevant for properly design such continuous reactors.

Some researchers have proposed the use of trickle bed reactors for three-phase advanced oxidation processes (e.g., catalytic wet air oxidation), pointing out some benefits such as low liquid to solid ratio and effective liquid-gas interaction (Maugans \& Akgerman, 2003). For example, Pintar, Batista \& Tisler (2008) reported TOC removal up to $98 \%$ for phenol solutions at $453 \mathrm{~K}$. In their experiments, catalyst deactivation was found to be significant (TOC conversion dropped to $41 \%$ after 28 hours). Other authors (Singh, Pant \& Nigam, 2004) achieved up to $50 \%$ of phenol degradation in a pilot plant trickle bed reactor using a copper oxide catalyst supported on alumina (60 cm bed length), finding a strong dependence of the system performance on the operation conditions (temperature, pressure, gas, and liquid flow rates). 
This paper investigates the use of a co-current down flow trickle bed reactor for heterogeneous catalytic ozonation of phenol. Fluid dynamics characterization (residence time distribution (RTD) and flow regime mapping) and phenol degradation studies were performed under different mass transfer conditions and geometrical configurations of the reactor. Two new catalysts (iron oxidediatomite pellets and iron oxide coated glass beads) were evaluated and compared against noncatalytic bed packings with similar geometries.

\section{MATERIALS AND METHODS}

\subsection{Reagents}

For the residence time distribution experiments, laboratory grade $\mathrm{NaCl}$ solutions were used as tracer. $3 \% \mathrm{~m} / \mathrm{m} \mathrm{Na}_{2} \mathrm{SO}_{4}$ solution was used to quench the ozonation reaction, and $\mathrm{NaOH}$ solution was used to adjust $\mathrm{pH}$ for phenol determination. $2 \% \mathrm{~m} / \mathrm{m} \mathrm{KI}$ solutions were utilized for gaseous ozone capture and determination.

\subsection{Catalyst preparation}

Iron-diatomite catalyst pellets (CPFe) were prepared using a variation of the method described by Maugans \& Akgerman (2003). Diatomite powder $\left(\right.$ Celite $\left.^{\mathrm{R}}\right)$ was mixed with Ludox binder colloidal silica (Sigma Aldrich) in a 1:1,5 m/v ratio to obtain a consistent paste. It was observed that such ratio minimizes the use of binder while keeping the needed consistency in the mixture. Cylindrical pellets were formed and calcinated a $325^{\circ} \mathrm{C}$ for 4 hours. The pellets were loaded with iron by incipient impregnation method using $\mathrm{Fe}_{2} \mathrm{SO}_{4}$ solutions. After 2 hours, impregnated pellets were calcinated for 4 hours at $325^{\circ} \mathrm{C}$ resulting in $6.38 \mathrm{~mm}$ equivalent diameter pellets with $0,77 \%$ $\mathrm{m} / \mathrm{m}$ iron load.

Iron-coated glass beads (CBFe) were prepared as follows: Glass beads $(5 \mathrm{~mm})$ were acid washed for 1 hour using $40 \%$ sulfuric acid solution. After thoroughly rinsing with distilled water, glass beads were dry at ambient conditions. For coating with iron oxide, the beads were submerged in $\mathrm{Fe}_{2} \mathrm{SO}_{4}$ solution ( $6 \% \mathrm{~F}_{2} \mathrm{SO}_{4} /$ mass of glass beads) for 2 hours, dried at $65^{\circ} \mathrm{C}$ for 2 hours, and calcinated at $325^{\circ} \mathrm{C}$ for 4 hours.

\subsection{Experimental Setup}

The experimental setup is comprised of a modified Reef Octopus Ozone Reactor (OR150), equipped with an interchangeable acrylic column $(39,0 \mathrm{~cm}$ height and 2,5 cm or 5,0 cm diameter) and packed with either cylindrical pellets or glass beads. The experimental setup also included gas and liquid flowmeters with regulation valves, ozone generator (Ozomax 1VTT), exhaust ozone destruction system, syringe for tracer input, and phenol and ozone sampling points at the liquid outlet (see Figure 1). The reactor was able to operate in the range from $0 \mathrm{~L} / \mathrm{min}-30 \mathrm{~L} / \mathrm{min}$ gas flowrate and $0,2 \mathrm{~L} / \mathrm{min}-0,5 \mathrm{~L} / \mathrm{min}$ liquid flowrate $(\mathrm{STP})$. 


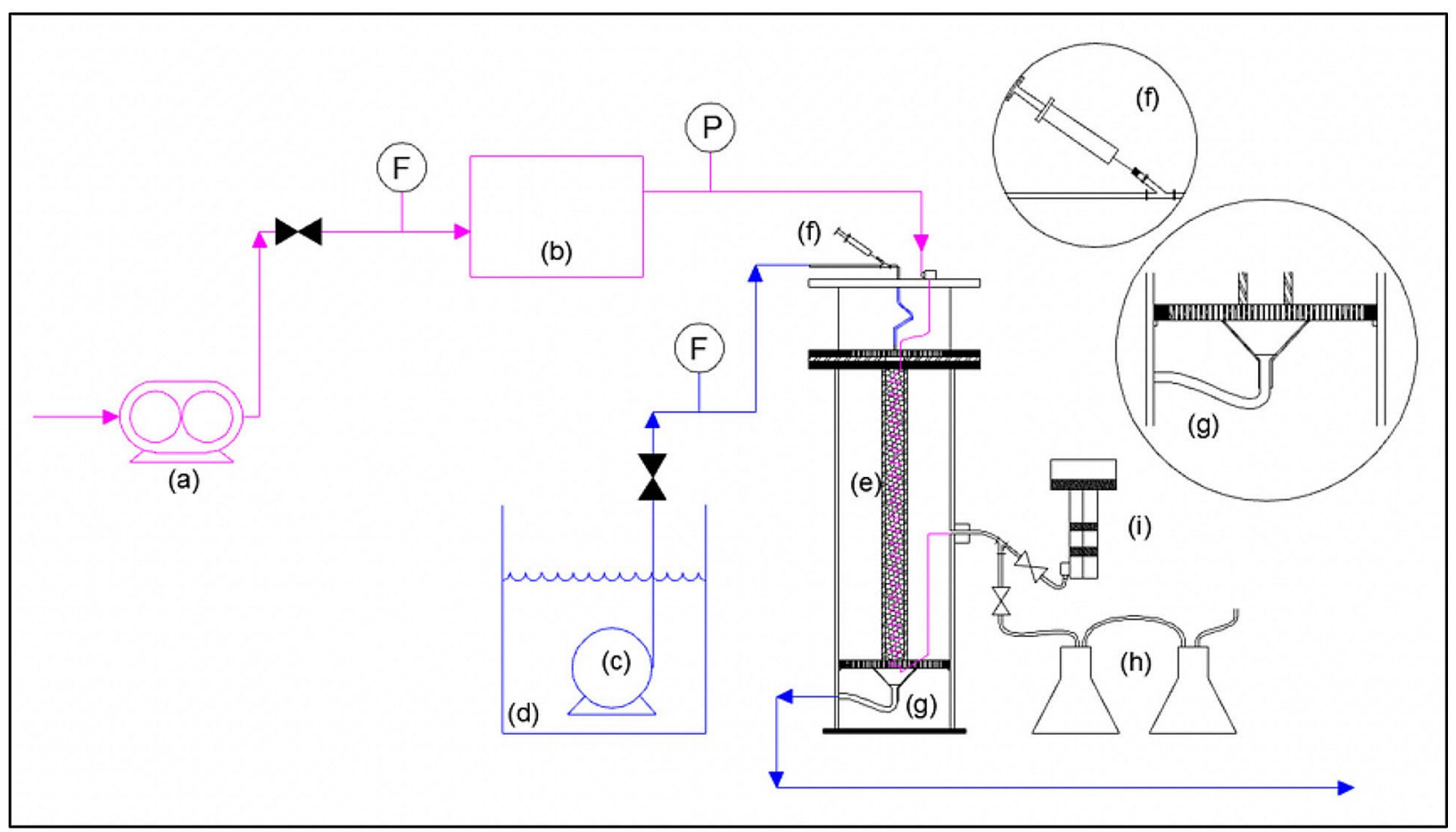

Figure 1. Experimental setup: (a) air compressor, (b) ozone generator, (c) submergible pump, (d) feed solution $5 \mathrm{~L}$ tank, (e) $2,5 \mathrm{~cm}$ internal column, (f) tracer injection point, (g) gas-liquid separator, (h) ozone sampler, (i) ozone off-gas destructor. F indicates in-line flowmeters and P manometers.

\subsection{Flow regime experiments}

Trickle bed reactor flow regime map was obtained by increasing gas flow rate $(0 \mathrm{~L} / \mathrm{min}-30 \mathrm{~L} /$ $\min )$ for a fixed liquid flow rate $(0,2 \mathrm{~L} / \mathrm{min}-0,5 \mathrm{~L} / \mathrm{min})$ until flow pulses were observed. All fluid dynamics experiments were performed using water as liquid and air as gas phase.

\subsection{RTD experiments}

The residency time distribution analysis was done following the pulse method described by Fogler (2008). For this, $\mathrm{NaCl}$ solution $(25100 \mathrm{mg} / \mathrm{L})$ was spiked at the reactor inlet and its concentration was measured at the outlet using a conductivity meter (Cole-Parmer CON 410).

\subsection{Phenol adsorption experiments}

Catalyst samples were sprayed with distilled/deionized water and then submerged in phenol solutions $(380 \mathrm{mg} / \mathrm{L}-410 \mathrm{mg} / \mathrm{L})$ in a 1:2 solid-liquid bulk volume ratio. Preliminary runs showed that, when using dry catalyst, air occluded in the particles affected negatively catalyst wetting. Dilution effect of spraying the pellets with water was considered negligible. In all adsorption experiments, phenol concentration was measured for 8 hours using a BioMate 3 spectrophotometer at $270 \mathrm{~nm}$ wavelength. Before measurements, all samples $\mathrm{pH}$ was adjusted to $6,84 \pm 0,05$ to block bathochromic shift effects or -OH group hydrolyzation. 


\subsection{Ozonation experiments}

In prior ozonation experiments, catalyst particles were left in contact with phenol stock solutions (400 mg/L - $450 \mathrm{mg} / \mathrm{L}$ ) overnight to reach adsorption equilibrium; in this way, any reduction of phenol concentration during reactor operation could be attributed to chemical (ozone) degradation. Initial phenol concentrations of around $400 \mathrm{mg} / \mathrm{L}$ were used so that experimental results could be comparable with other studies (Pintar, Batista \& Tisler, 2008). Liquid and gas flows in the reactor were let to reach stability before the ozone generator was turned on. For all ozonation experiments, samples were taken during steady state operation. Liquid outlet samples were taken for dissolve ozone (Ozone Pocket Colorimeter, HACH) and phenol analysis, and gas outlet samples were collected for ozone determination by iodimetric titration (Rakness et al., 1996).

\section{RESULTS AND DISCUSSION}

\subsection{Catalysts}

Mechanical strength of the iron-diatomite catalyst pellets was adequate to withstand column packing weight and operation; thus, no fracture or particle deformation was observed. Iron content was measure for both $\mathrm{CPFe}$ and CBFe catalysts by ICP-MS analysis, resulting in $(0,77 \pm 0,01) \% \mathrm{~m} / \mathrm{m}$ for the CPFe pellets and $(0,0079 \pm 0,0010) \% \mathrm{~m} / \mathrm{m}$ for the CBFe beads. Iron loading in CBFe beads was expected to be much lower since iron is deposited only on the external surface of glass beads, whereas pellets are made of a porous material and deposition takes place inside the pellets too. Iron lixiviation was not observed during reactor operation. Equivalent diameter of the cylindrical pellets was $6,38 \mathrm{~mm}$ : this particle size was small enough for having good liquid distribution, low pressure drop, and trickle bed flow conditions as showed in the hydrodynamic studies. $\mathrm{pH}$ changes in phenol solutions suggest a correlation between acidic sites in the catalyst surface and solid-liquid interaction since a significant $\mathrm{pH}$ change was observed as soon as phenol solution and catalyst were put in contact, varying from 6,2 to 4,0 . This behavior was not observed when using spherical glass beads.

\subsection{Flow regime map}

Typically, in a trickle bed reactor, four different flow regimes (spray, trickle, pulsing, and bubbling) can be observed, characterized by liquid or gas phase continuity. Flow regime present in a specific reactor depends on the throughput of the phases, bed and particle geometrical characteristics, and fluids physical properties. In most industrial applications, trickle bed reactors are operated under trickle or pulsing flow conditions because high mass and heat transfer rates can be achieved in such fluid flow conditions. Stagnant liquid holdup mobilization in pulsing flow has been reported to enhance reactor performance, increase catalyst usage, and reduce axial dispersion (Gunjal, Ranade \& Chaudhari, 2003).

Phase continuity and pulse presence were studied to construct a flow regime map for the trickle bed reactor used; in this way, proper operation conditions were identified. As shown in Figure 2, 
the reactor can be operated in either trickle or pulsing flow regimes. It was found that increasing bed diameter leads flow regime transitions at higher gas velocities and that particle geometry plays an important role as the effect of diameter was bigger for the pellets. These observations are in accordance with those reported by Boelhouwer, Piepers \& Drinkenburg (2002).

As it can be observed, 0,025 m diameter column presents pulsing flow in most of its operation range. These results suggest that this reactor configuration presents favorable conditions for HCO since pulsing flow conditions are suitable for fast reactions (Boelhouwer, Piepers \& Drinkenburg, 2002).

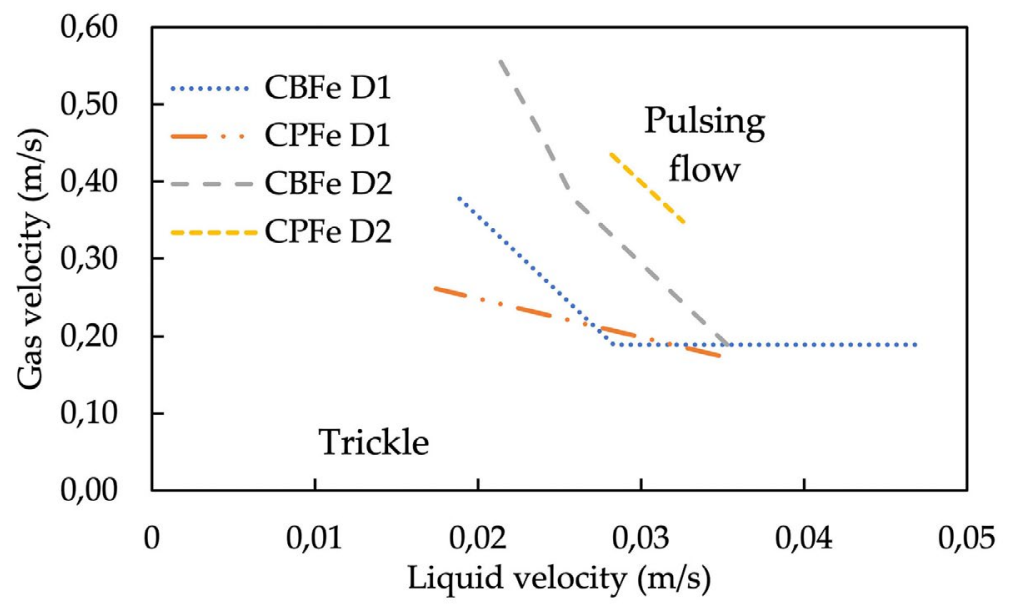

Figure 2. Flow regime map for glass beads and pellets with column diameters of $0,025 \mathrm{~m}(\mathrm{D} 1)$ and $0,05 \mathrm{~m}$ (D2).

\subsection{RTD Analysis}

In order to establish the effect of geometry on the hydrodynamic behavior of the trickle bed reactor, a residence time distribution analysis was performed using two column diameters $(0,025$ $\mathrm{m}$ and $0,050 \mathrm{~m}$ ), and two particle geometries $(5 \mathrm{~mm}$ diameter glass beads and $5 \mathrm{~mm}$ equivalent diameter acrylic pellets), operating the reactor under pulsing flow regime. The n-CSTR model (Eq. 1) and the axial dispersion model (ADM) (Eq. 2) (Wanchoo, Kaur, Bnasal \& Thakur, 2007) were fitted to the experimental data as shown in Figure 3.

$$
E_{n-C S T R}(t)=\frac{1}{t_{m}} \frac{N\left(N\left(\frac{t}{t_{m}}\right)\right)^{N-1}}{(N-1) !} \exp \left(-N\left(\frac{t}{t_{m}}\right)\right)
$$


$E_{A D M}(t)=\frac{1}{t_{m}} \sqrt{\frac{P e}{4 \pi\left(\frac{t}{t_{m}}\right)}} \exp \left(\frac{-P e\left(1-\left(\frac{t}{t_{m}}\right)\right)^{2}}{4\left(\frac{t}{t_{m}}\right)}\right)$

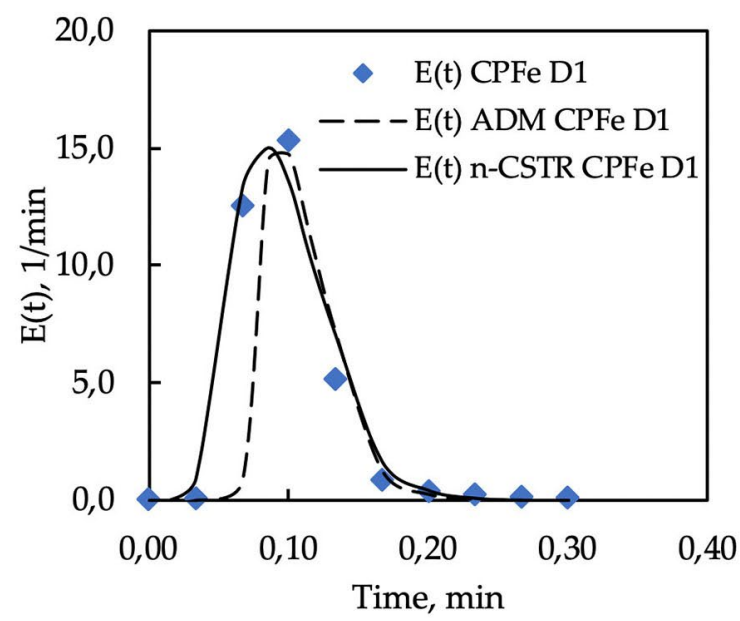

(a)

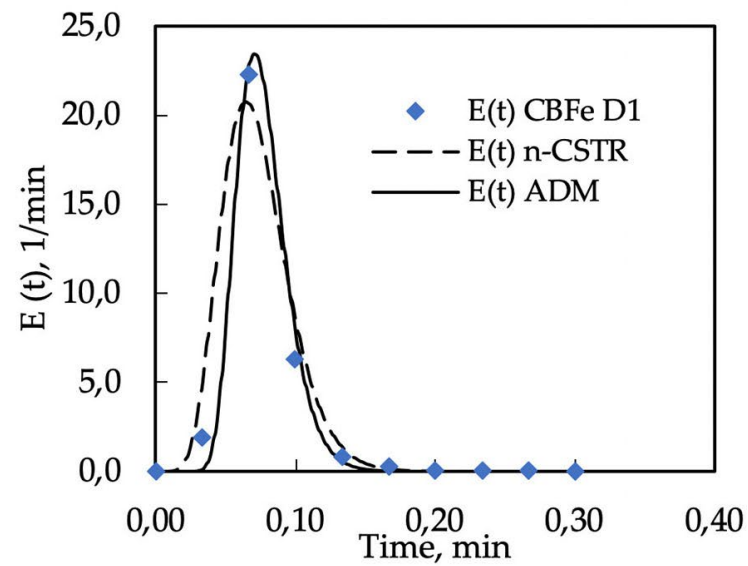

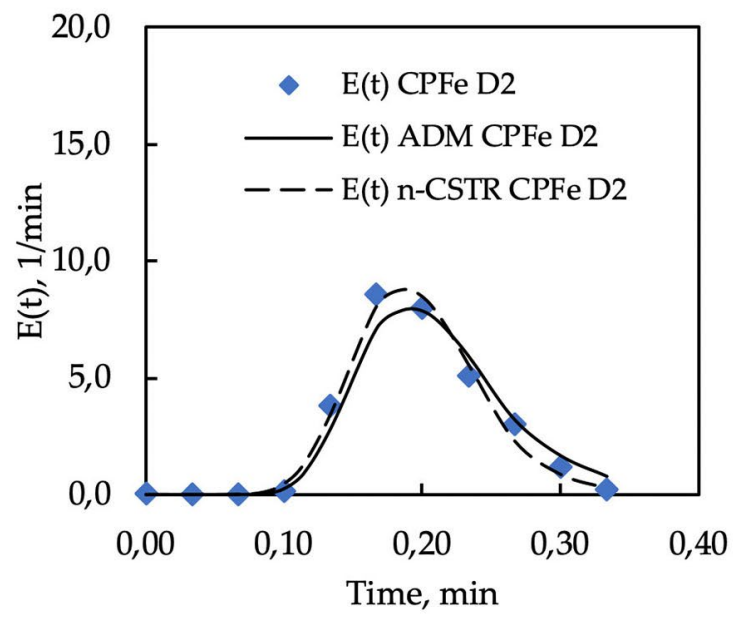

(b)

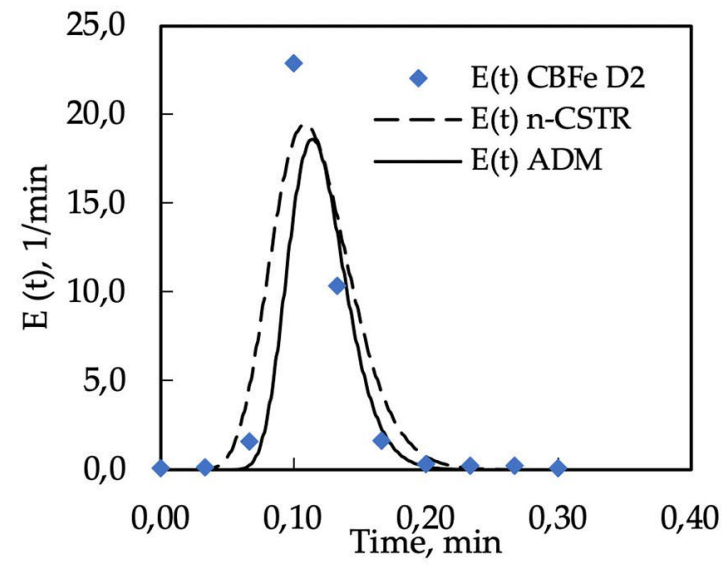

Figure 3. RTD data and n-CSTR and ADM model predictions for the 0,025 m (D1) and 0,050 m (D2) diameter columns, filled with CPFe pellets ((a) and (b)) and CBFe glass beads ((c) and (d)). Liquid flow rate $=0.3 \mathrm{~L} / \mathrm{min}$ and gas flow rate $=8,0 \mathrm{~L} / \mathrm{min}$.

Table 1 shows the Péclet number $(\mathrm{Pe}), \mathrm{N}$ parameter, experimental mean residence time $\left(\tau_{m}\right)$, variance $\left(\sigma^{2}\right)$, and skewness $\left(s^{3}\right)$ for the studied configurations. Table 2 shows the standard error and $\mathrm{R}^{2}$ values for the fitted models. When the obtained Pe values are compared with those reported by Perry \& Green (2008) for pilot plant reactors and by inspecting the sharpness of the curves (see also the standard deviations), it can be deducted that axial dispersion is low in the experimental system. This behavior is in accordance with that expected for trickle bed reactors operating under 
pulsing flow conditions because of the reduction of stagnant liquid holdup and increase of radial mixing (Boelhouwer, Piepers \& Drinkenburg, 2002).

Table 1. RTD moments, Pe and $N$ values obtained for the $0,025 \mathrm{~cm}(D 1)$ and $0,050 \mathrm{~cm}(D 2)$ columns.

\begin{tabular}{cccccccc}
\hline Geometry & $\tau_{\mathrm{m}}(\mathrm{min})$ & $\mathrm{Pe}_{\mathrm{ADM}}$ & $95 \% \mathrm{CI}(\mathrm{Pe})$ & $\mathrm{N}_{\mathrm{N}-\mathrm{CSTR}}$ & $95 \% \mathrm{CI}(\mathrm{N})$ & $\sigma^{2}$ & $\mathrm{~s}^{3}$ \\
\hline CBFe D1 & 0,073 & 36,22 & 6,75 & 9,09 & 0,06 & 0,0006 & 0,0110 \\
$\mathrm{CBFe} D 2$ & 0,116 & 58,32 & 0,02 & 15,13 & 0,08 & 0,0009 & 0,0082 \\
$\mathrm{CPFe}$ D1 & 0,097 & 24,31 & 0,04 & 8,11 & 0,05 & 0,0012 & 0,0112 \\
\hline CPFe D2 & 0,198 & 32,50 & 0,03 & 19,00 & 0,02 & 0,0020 & 0,0042 \\
\hline
\end{tabular}

Table 2. Standard error and $R^{2}$ values obtained for the ADM and $N$-CSTR model fitting.

\begin{tabular}{ccccc}
\hline Geometry & $\mathrm{SE}_{\mathrm{ADM}}$ & $\mathrm{SE}_{\mathrm{N}-\mathrm{CSTR}}$ & $\mathrm{R}^{2}{ }_{\mathrm{ADM}}$ & $\mathrm{R}_{\mathrm{N}-\mathrm{CSTR}}$ \\
\hline CBFe D1 & 0,873 & 1,306 & 0,985 & 0,963 \\
CBFe D2 & 3,027 & 2,550 & 0,815 & 0,898 \\
CPFe D1 & 3,765 & 0,938 & 0,904 & 0,976 \\
\hline CPFe D2 & 0,751 & 0,514 & 0,950 & 0,983 \\
\hline
\end{tabular}

Mean residence times showed the effect of geometry (particle size and shape, and column diameter) on the hydrodynamic behavior. It was found that $\tau_{m}$ increases when increasing the column diameter and that it is higher for the pellets than the beads. This result suggests that higher mean residence times can be achieved when increasing bed tortuosity (cylinder vs. spherical particles), leading to higher contact times and promoting pollutant conversion for the same column diameter. However, when comparing the beads against the pellets for the same column diameter, Pe number is consistently higher, suggesting lower axial dispersion. In this case, the more regular geometry of beads allows a more even flow through the reactor. This behavior is also observed when increasing the column diameter for the same particle geometry, possibly due to decreased wall effects. 


\subsection{Phenol degradation by catalytic ozonation}

In the ozonation experiments, the three processes through which phenol disappears from solution were evaluated independently for better comparing the catalysts performance (i.e., phenol adsorption over the solid catalyst, phenol degradation by direct ozonation, and phenol degradation by heterogeneous catalytic ozonation). For evaluating degradation only by direct ozonation, the reactor was filled and operated with a non-catalytic packing of comparable size and shape as the catalyst pellets and beads.

Phenol adsorption measurements for the CPFe pellets are shown in Figure 4. As can be seen, phenol adsorption over the diatomite pellets was important with nearly $16 \%$ drop in its concentration after 8 hours. On the other hand, phenol adsorption on the CBFe beads was negligible and therefore the data are not shown. Based on these results, for all the following ozonation runs, phenol solutions were left in contact overnight (12 hours) with the catalysts, allowing adsorption equilibrium to be reached prior to the reaction with ozone. In this way, it can be assumed that all phenol abatement in the ozonation experiment can be attributed to either direct or catalytic ozonation.

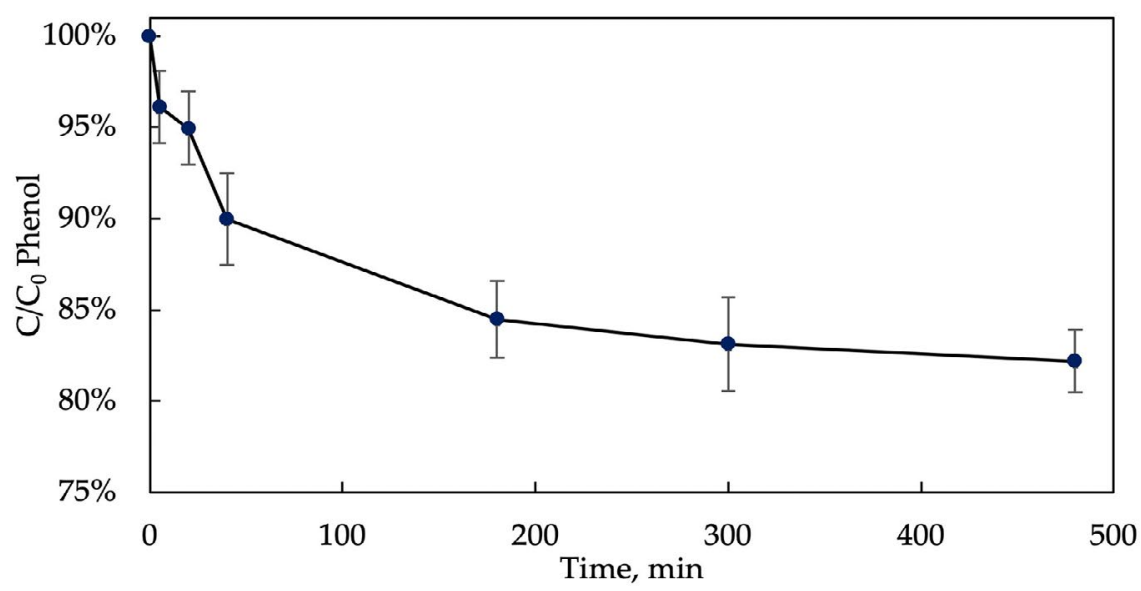

Figure 4. Phenol adsorption on CPFe catalyst pellets in batch mode. Initial phenol concentration $=387 \mathrm{mg} / \mathrm{L}$ with a $1: 2$ solid-liquid bulk volume ratio. Error bars represent standard deviation $(n=3)$.

Ozonation experiments were performed using four different configurations: spherical noncatalytic packing, spherical catalytic packing, cylindrical non-catalytic packing (acrylic cylinders), and cylindrical catalytic packing (iron-loaded diatomite pellets). All runs were performed under the same flow conditions: $8,0 \mathrm{~L} / \mathrm{min}$ gas and $0,3 \mathrm{~L} / \mathrm{min}$ liquid flowrates $\left(\tau_{\mathrm{m}}=0,0965 \mathrm{~min}\right.$ for the cylindrical packing, $\tau_{\mathrm{u}}=0,0730 \mathrm{~min}$ for the spherical packing). From the results shown in Figure 5, it can be stated that the presence of iron oxide on any packing leads to an improvement in phenol conversion: from $13.3 \%$ to $19.7 \%$ for $\mathrm{CPFe}$ and from $15.9 \%$ to $19.5 \%$ for $\mathrm{CBFe}$. This result demonstrates a better performance of catalytic over direct ozonation ( $48,1 \%$ for the case of $\mathrm{CPFe}$ ). Moreover, when both particles containing iron ( $\mathrm{CPFe}$ and $\mathrm{CBFe}$ ) are compared, no significant difference was observed; this suggests that the presence of iron oxide in the particle plays a greater role than its geometry. 


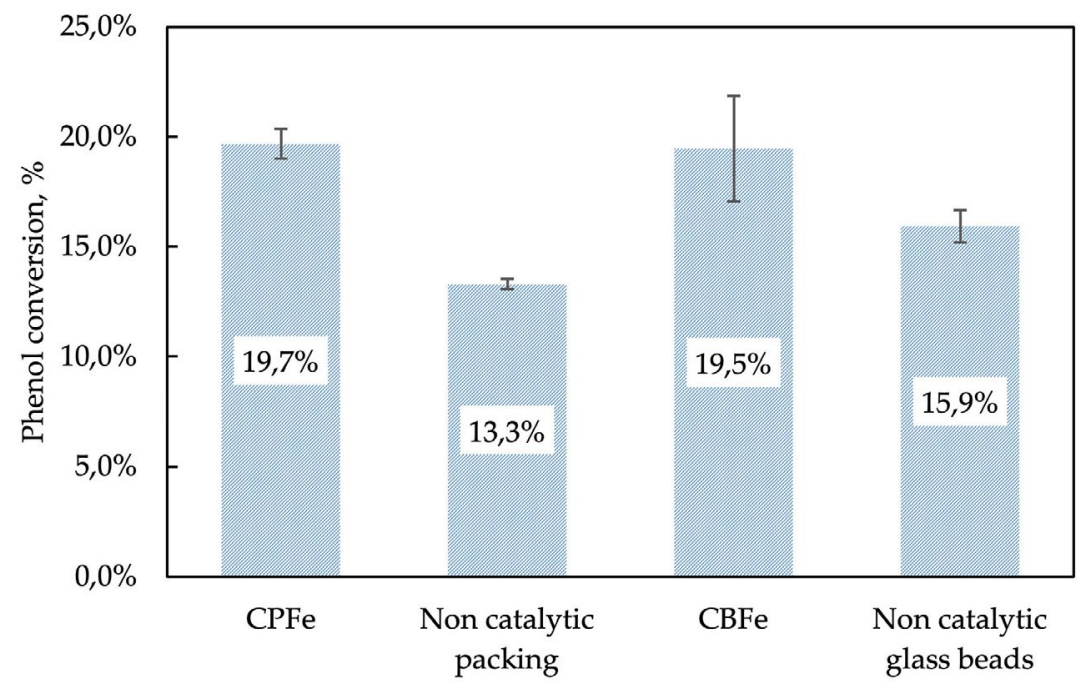

Figure 5. Phenol conversion under steady state operation for different column packings. Liquid flowrate $=0,3 \mathrm{~L} / \mathrm{min}$, gas flowrate $=8,0 \mathrm{~L} / \mathrm{min}$, initial phenol concentration $=431 \mathrm{mg} / \mathrm{L}$, diameter column $=0,025 \mathrm{~m}$. Error bars represent standard deviation $(\mathrm{n}=3)$.

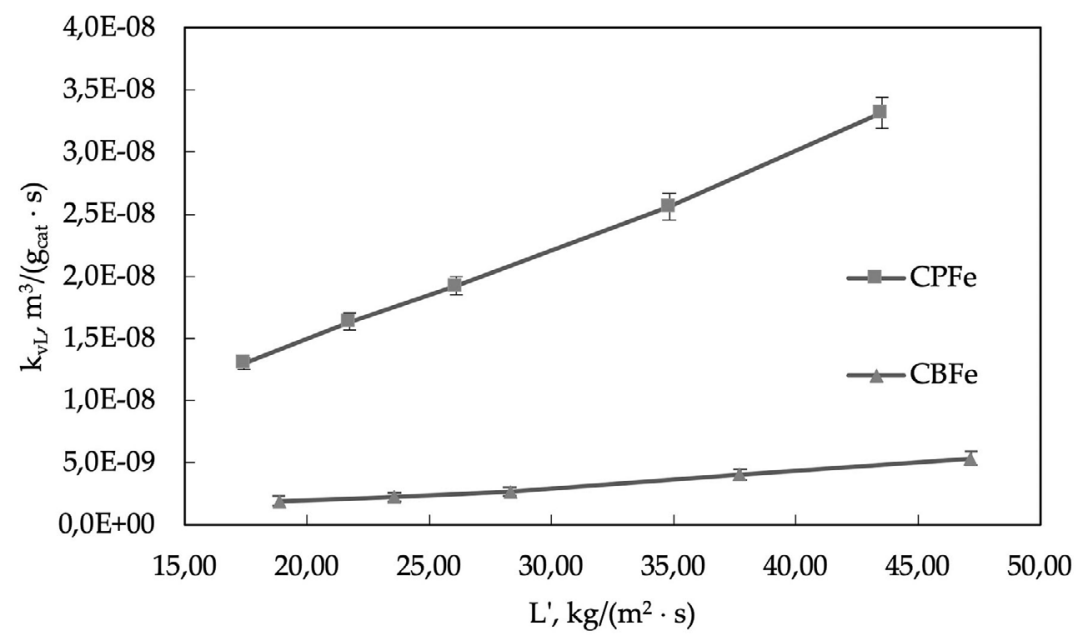

Figure 6. Dependence of phenol overall mass transfer coefficient with liquid mass flux for the 0,025 $\mathrm{m}$ diameter column packed with $\mathrm{CPFe}$ and $\mathrm{CBFe}$. Error bars represent standard deviation $(\mathrm{n}=3)$.

In order to investigate the effect of mass transfer on the reactor performance, experiments were carried out varying the liquid flowrate. No significant change in phenol conversion was observed under different flowrates. This result evidences that mass transfer effects are important in this system; therefore, the overall mass transfer coefficient from bulk liquid to the particle surface $\left(\mathrm{k}_{\mathrm{vL}}\right)$ was determined for better analysis. This overall coefficient was calculated as presented by Fogler (2008), assuming pseudo first order reaction for the catalytic ozonation and considering 
that the liquid phase was saturated with ozone gas throughout the column. Figure 6 shows that for the porous catalyst (diatomite pellets) an increase in flowrate leads to an increase in the overall mass transfer coefficient. For the glass beads, on the other hand, the change of $\mathrm{k}_{\mathrm{vL}}$ with the liquid flowrate is almost negligible. It is theorized that pulsing flows induce higher internal mass transfer in porous media due to capillary pressure effects. Such phenomena would not be present in the case of non-porous particles. These results suggest that, under certain flow conditions, the performance of the reactor could be significantly improved when using porous pellets.

\section{CONCLUSIONS}

In this contribution, the results on the use of a trickle bed reactor for the heterogeneous catalytic ozonation of phenol were shown. It was found that:

- $\quad$ Fluid dynamics studies showed that the reactor could operate under trickle and pulsing flow regimes.

- $\quad$ RTD data showed that under pulsing flow regime, axial dispersion was low when compared with other reactors. Experimental data were better described by the n-CSTR model.

- $\quad$ The synthetized Fe-diatomite catalyst showed important phenol adsorption (16\%).

- $\quad$ Trickle bed reactor effectively decreases phenol concentration (19,7\% conversion with a liquid-phase space time of just 6 seconds).

- $\quad$ The use of the Fe-diatomite catalyst enhanced the reactor performance by $48 \%$ when compared to direct ozonation.

\section{ACKNOWLEDGMENTS}

The authors would like to acknowledge the help and support from: Research Center of Electrochemistry and Chemical Energy (CELEQ) and Research Vice-rectory of the University of Costa Rica.

\section{REFERENCES}

Babu, D. S., Srivastava, V., Nidheesh, P., \& Kumar, M. S. (2019). Detoxification of water and wastewater by advanced oxidation processes. Science of The Total Environment, 696, 133-961.

Boelhouwer, J., Piepers, H., \& Drinkenburg, A. H. (2002). Nature and characteristics of pulsing flow in trickle-bed reactors. Chemical Engineering Science, 57, 4865-4876.

Fogler, H. S. (2008). Elements of Chemical Reaction Engineering. Ann Arbor: Pearson Education.

Gunjal, P., Ranade, V., \& Chaudhari, R. (2003). Liquid Distribution and RTD in Trickle Bed Reactors: Experiments and CFD Simulations. The Canadian Journal of Chemical Engineering, 81, 821-830.

Li, B., Xu, X., Zhu, L., Ding, W., \& Mahmood, Q. (2010). Catalytic ozonation of industrial wastewater containing chloro and nitro aromatics using modified diatomaceous porous filling. Desalinization, 254, 90-98.

Maugans, C. B., \& Akgerman, A. (2003). Catalytic wet oxidation of phenol in a trickle bed reactor over a Pt/TiO2 catalyst. Water Research, 37, 319-328.

Perry, R. H., \& Green, D. W. (2008). Perry's chemical engineers' handbook. New York: McGraw-Hill. 
Peña-Guzmán, C., Ulloa-Sánchez, S., Mora, K., Helena-Bustos, R., Lopez-Barrera, E., Alvarez, J., \& Rodriguez-Pinzón, M. (2019). Emerging pollutants in the urban water cycle in Latin America: A review of the current literature. Journal of Environmental Management, 237, 408-423.

Pintar, A., Batista, J., \& Tisler, T. (2008). Catalytic wet-air oxidation of aqueous solutios of formic acid, acetic acid and phenol in a continuous-flow trickle-bed reactor over $\mathrm{Ru} / \mathrm{TiO}_{2}$ catalysts. Applied Catalysis B: Environmental, 84, 30-41.

Rakness, K., Langlais, B., Masschelein, W., Matsumoto, N., Richard, Y., \& Somiya, I. (1996). Guideline for measurement of ozone concentration in the process gas for an ozone generator. Ozone Science \& Engineering, 18, $209-229$.

Singh, A., Pant, K. K., \& Nigam, K. P. (2004). Catalytic wet oxidation of phenol in a trickle bed reactor. Chemical Engineering Journal, 103, 51-57.

Wanchoo, R. K., Kaur, N., Bnasal, A., \& Thakur, A. (2007). RTD in trickle bed reactors: experimental study. Chemical Engineering Comm., 194, 1503-1515.

Zeng, Z., Zou, H., Li, X., Sun, B., Chen, J., \& Shao, L. (2012). Ozonation of phenol with O3/Fe(II) in Acidic Environment in a Rotating Packing Bed. Industrial \& Engineering Research, 51, 10509-10516.

Zhao, L., Ma, J., Zhizhong, S., \& Zhai, X. (2008). Mechanism of influence of initial pH on the degradation of nitrobenzene in aqueous solution by ceramic honeycomb catalytic ozonation. Environmental Science and Techonology, 42, 4002-4007. 